\title{
Developing Broad Business Perspective Competencies By Partnering With Practitioners
}

Richard Cummings, (Email: cummingr@uww.edu), University of Wisconsin, Whitewater Mark W. Miller, (Email: mmiller@KolbCo.com), Kolb \& Co. Business Advisers/CPAs SC

\begin{abstract}
The CPA Vision Project - 2011 and Beyond) is a blueprint for the accounting profession of the $21^{\text {st }}$ Century. From this visioning process the AICPA Core Competency Framework for Entry into the Accounting Profession (1999) was developed. It is from this framework that accounting educators are invited to adjust curriculum to provide students with the opportunity to develop these functional, personal, and broad business perspective core competencies so that students can meet the accounting profession challenges of the $21^{\text {st }}$ century.

This paper provides a specific model for developing broad business perspective competencies by partnering with a practitioner. Although using professionals in the classroom is not a new idea, this paper offers a unique perspective of the process by juxtaposing the perspectives of the academic and the practitioner in the processes of developing the partnership, planning the classroom event (which includes developing the broad business perspective competencies), designing and collecting student feedback, and evaluating the results of the classroom event and partnership.
\end{abstract}

\section{INTRODUCTION}

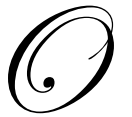

ver the past quarter of a century accounting educators have been urged to change their pedagogy so accounting students might be better able to adapt to future demands of the accounting profession (Accounting Education Change Commission, 1990; Big Eight White Paper, 1989; American Accounting Association Committee on the Future Structure, Content, and Scope of Accounting Education, 1986). The response of the accounting profession has been that the American Institute of Certified Public Accountants (AICPA), and state societies, have worked together in getting grassroots participation to develop the CPA Vision Project - 2011 and Beyond (1998), which is a blueprint for the accounting profession of the $21^{\text {st }}$ century. From this visioning process the AICPA Core Competency Framework for Entry into the Accounting Profession (1999) was developed. It is from this framework that accounting educators are invited to adjust curriculum to provide students with the opportunity to develop these functional, personal, and broad business perspective core competencies so that students can meet the accounting profession challenges of the $21^{\text {st }}$ century.

Functional and personal core competencies are developed by Fouch (2004) when an interactive tax research case is used in the classroom to role play the different stakeholder scenarios in a mock tax court. While Kramer and Johnson (2005) more broadly discuss the link between the practitioner and the professional in the areas of:

- $\quad$ Influencing the academic curriculum by discussing current practice needs

- $\quad$ Collaborating with faculty on advisory boards

- $\quad$ Becoming involved with students through classroom visits, career mentoring, and funding of accounting club projects. 
This paper provides a specific model for developing broad business perspective competencies by partnering with a practitioner. Although using professionals in the classroom is not a new idea, this paper offers a unique perspective of the process by juxtaposing the perspectives of the academic and the practitioner in the processes of developing the partnership, planning the classroom event (which includes developing the broad business perspective competencies), designing and collecting student feedback, and evaluating the results of the classroom event and partnership.

\section{Developing the Partnership}

Albrecht and Sack (2000) remind us that "[w]e need to look for creative ways to involve business professionals in the educational process...” It is important for a working partnership to be established between the accounting faculty member and the practicing CPA to bring about the classroom event that will develop broad business perspective competencies for students. This partnership process can be much more beneficial than taking chances with a new presenter each semester. Highlighted below are two perspectives from the accounting faculty member (professor) and the CPA (practitioner) on how to develop the partnership to support the classroom event.

\section{Professor's Perspective}

Finding the Right Practitioner. Characteristics of an ideal practitioner would include: engaging and effective speaker, actively involved in doing accounting (in this case it was tax accounting), committed to the professor's and students' university, flexible in collaborating with faculty member to design and improve classroom event, and motivated by the value to students and the firm that the classroom event will provide.

Alumni, state and national CPA organizations, advisory board members, students' parents or friends, and oncampus recruiters are just a few of the resources for finding an individual who might be the "right practitioner". Yet these resources may not provide a venue to see the practitioner in action. A Beta Alpha Psi or accounting club meeting may provide a good forum where invited speakers can be assessed in light of the above-mentioned criteria. This process will take a bit of the risk out of the classroom event since it will provide a good idea how the practitioner relates to students and the amount of time he or she might be willing to spend in developing a quality classroom event.

When the right practitioner is found the students will benefit from "real world" experiences the practitioner shares. In many cases those experiences will reinforce topics the professor has already covered in class.

\section{Practitioner's Perspective}

Motivation for getting involved. There are many benefits that can be realized by the practitioner from partnering with the professor in designing the classroom activity. The primary motivation of the practitioner undoubtedly revolves around the positive impact on recruiting students as future interns or employees to the practitioner's firm. The classroom provides the practitioner with the opportunity to keep the firm's name in front of the students. If the classroom presentation is scheduled to be proximate to the time the firm will be involved in the recruiting process for interns or full-time employees, the benefit of participating is further enhanced. The classroom participation allows the practitioner to showcase the firm's expertise and communicate its work culture. The practitioner's involvement in the classroom may also be considered a tool to encourage more students to pursue a career in the field of public accounting. In addition, the students are likely to view the invitation by the professor as an endorsement by the faculty of the quality of the practitioner's firm.

The practitioner-professor partnership also allows the practitioner to solidify the relationship with the departmental faculty. It provides the opportunity to identify the top candidates in the program. The practitioner also has the opportunity to give back to the university as a thank-you for alumni who have selected the practitioner's firm as a place of employment. 


\section{PLANNING THE CLASSROOM EVENT}

It is critical for the professor and practitioner to develop their own objectives for the classroom event and discuss effective strategies for delivery of content. This collaboration provides an opportunity to discuss the AICPA Core Competency Framework, especially the broad business perspectives competencies.

\section{Professor's Perspective}

\section{Broad Business Perspective Competencies Developed in the Classroom Event}

- $\quad$ Strategic/Critical Thinking. Issues such as the practitioner firm's vision, strategy, goals, and culture of the organization can be easily introduced as part of the introduction to the speaker. This provides a "real world" example of how firms strategically manage.

Example: In our experience, Mark was introduced as the Managing Director of the Tax Division, of Kolb \& Co. CPAs. He explained that the firm's vision is to provide integrated services for business; his part of that vision is to develop strategies in the tax and wealth management areas to provide for the needs of his clients. Since Mark is heavily involved in recruiting college students for internships and full-time employment, his perspective on the expectation or goals for new hires is very relevant to students. Typically, Mark presents with one of our recent accounting graduates who is working for Kolb; a natural discussion flows on the culture at Kolb or what is it like to work there fresh out of college.

- Industry and Legal/Regulatory Perspective. Practitioners can provide value to students by explaining the current competitive environment in the financial services profession. The last few years have provided a watershed of new laws that affect the accounting profession. With the new Sarbanes-Oxley regulations, coupled with almost annual tax law changes, the practitioner can provide reinforcement of the content of the legislation along with a very timely and relevant discussion of how practitioners see the opportunities and risks associated with these changes in the industry.

Example: The Top-10 list of new tax law changes relevant to Mark's clients has been a favorite for the students. Mark has generated some enthusiasm by asking students why a certain new tax law change will be valuable to taxpayers. He rewards students with correct answers with company pens, yo-yo's, key chains, can coolers, or a mini etch-a-sketch. A friendly competitiveness develops among the students for the prizes while engaging the students in seeing and thinking about changes in the profession. Sometimes Mark follows up the discussion with an anonymous client story that adds life to the issue.

- $\quad$ Leverage Technology to Develop and Enhance a Broad Business Perspective. How do accounting professionals use technology to effectively operate their organizations? One venue many organizations have used is the development of an internet site that provides information for potential customers. Using the internet and e-mail is nothing new to our students; however, the tax return prepared in a paperless environment is something that is new.

Example: This past semester, Mark was able to simulate the process of preparing a paperless tax return. Students in the class were able to see the software that was used in preparing the return and hear about the changes that were necessary to provide for scanning of source documents and sharing the returns electronically. Students were able to understand the operational efficiency of having a database of client information available from different locations for staff purposes. Students immediately asked the cost-benefit question. This discussion highlighted the time savings in locating, physically moving, and storing previous paper returns. In addition, the ease of sending an electronic return to a customer or approved customer creditor highlighted the time savings for this process. Surprisingly, it was the students who asked questions about the security of the data and client comfort with the new technology.

- International/Global Perspective. The paperless tax return led us into the timely issue of outsourcing tax returns to accountants around the globe. The issues of data security and client comfort very much apply to 
this situation. The other side of the coin is the human resource management efficiencies this process provides. Since most tax returns are prepared in the first four months of the year, outsourcing can provide an effective way of providing additional human resources at peak demand times, thus providing staffing flexibility. This topic is certain to be explored in future classroom events.

- $\quad$ Marketing/Client Focus. Marketing and client focus is a priority for most financial service organizations. Anticipating and meeting the changing needs of clients in a rapidly changing legal and regulatory environment is the goal of most firms.

Example: In our classroom event students are required to bring three typed questions for our presenters to discuss. This provides resources for the question and answer part of the classroom event. Students are free to ask anything about the profession, taxation, accounting, the individual firm, or whatever they think is important. A question that is usually asked of the recent graduate is, "What is your day like?" This answer usually provides students with an idea of employer/client protocol and job expectations. Client focus was really brought home one semester when the new staff person could not come because she had to finish a client's tax return. This developed into a discussion about putting client's needs first and the time demands of the profession.

\section{Structure of the Classroom Event}

Over the past few years we have found some activities that have worked for us. These activities are discussed and listed below.

- $\quad$ Question and Answer. Students generally like having the opportunity to ask practitioners questions. Initially, when they read the required assignment to bring three typed questions to the session they are not quite sure of the types of questions. Throughout the class, we promote the idea of students getting a second opinion on any issue we discuss when the CPAs visit the classroom. In addition, announcing the event a week before it happens provides a forum to discuss the assignment. Having the questions prepared assures legibility for the presenters and a wealth of students' issues to discuss. Many times the presenters toss the question back to the students to see if anyone knows the answer.

- $\quad$ Interactive Activity. Having an interactive activity can provide a break from reading and answering questions. We have used interactive tax trivia quizzes that students fill out at the beginning of class. The questions are asked during class and the student with the correct answer receives a door prize from the firm. The student with the most correct answers is also provided a door prize. The questions are usually interspersed with the question and answer activity to provide some breaks.

- $\quad$ Special Topic. The paperless tax return is a good example of a special topic; it was best presented using the software so students could actually see what professionals see when they are preparing a paperless return. The process along with the software was discussed. Students were then allowed to ask questions. This was used as the opening topic of the classroom event in addition to questions and answers and an interactive activity.

The key is to provide an opportunity where students are engaged and enjoying the experience. We usually hold this event in the last few weeks of the semester, since generally the students know more about taxes and have more questions toward the end of the course.

\section{Practitioner's Perspective}

- $\quad$ Meaningful but not Time consuming Presentations. The practitioner will want to be associated with an activity that is perceived as worthwhile by the students. The presentation or activity needs to be fresh (not canned), timely, and one that limits the amount of advanced preparation. This enables the practitioner to differentiate the firm from others that may give presentations at other accounting-related events. Typically, 
the practitioner is able to limit the classroom preparation time to 3-5 hours including the development of a tax-trivia quiz or special feature such as the "paperless return preparation process."

- Leveraging the Experience. If the professor teaches multiple sessions of the same class, it allows the practitioner to multiply his or her exposure to students with little additional time involvement.

\section{DESIGNING AND COLLECTING STUDENT FEEDBACK}

\section{Professor's Perspective}

In the first few semesters Mark made his presentation we used oral feedback. In the first class after the classroom event, students were individually asked for feedback. The whole class voted on whether the speaker should be invited back for next semester's students; they unanimously voted to have the speaker return next semester. Spring semester of 2005 was the first semester we used an open-ended written survey. Students were asked what things they found helpful from the presentation, what things they would change for future presentations, and whether they would invite the speaker back for next semester's tax class. The results of these questions will be addressed in the next section on the results of the classroom event.

\section{Practitioner's Perspective}

This past semester, we shared the written student feedback. This allowed us to assess the benefit derived by the firm as well as consider modifications for future programs. It has definitely been a positive reinforcement for continued involvement in the classroom event. The data has provided feedback as to the student's primary area of interest whether it be technical, career opportunities, or what busy-season is like in public accounting.

\section{RESULTS OF CLASSROOM EVENT}

\section{Professor's Perspective}

Exhibit 1 lists student responses regarding what things they found helpful about the presentation. It is easy to see that many examples of the broad business perspective competencies are listed here. The strategic competencies can be seen in the many comments on organization culture, lifestyles, teamwork, internship, and employment expectations. Industry and legal/ regulatory perspective competencies can be seen in student comments about 'real world' experiences, changes in the accounting profession, and ethical issues. Leveraging technology competencies can be seen in student comments about the paperless tax return presentation, how professionals use their computer systems to make their analysis, and future tax software available to students. International and global perspectives competencies also appeared in the class discussion about the security and portability of electronic information which brings us to next semester's topic of outsourcing work to foreign countries. Marketing and client focus competencies was a pervasive topic which shows up in student comments about career expectations and handling "busy season" issues. The student responses suggest that for the most part students seemed to like the question and answer format with the focused discussion on the paperless tax return, interspersed with the tax trivia quiz. The student comment, "Discovering that everything covered in our class does have a 'real world' application" was particularly noteworthy.

Exhibit 2 identifies student comments about what things could be improved for future presentations. It is interesting to note that $36 \%$ (twenty-three of the sixty-four respondents) recommend that no change be made to the presentation. Other student comments suggested more time be devoted to answering student questions or providing information on career opportunities.

Exhibit 3 provides a "bottom line" analysis of the event. Nearly $97 \%$ of the student respondents suggested we invite the speakers back for the class next semester. The two students who did not vote yes were indifferent. One of those students was a non-accounting major and was interested in a speaker from his major area while the other student suggested we have more than one firm making the presentation. 


\section{Practitioner's Perspective}

We have consistently indicated a desire to continue the professor-practitioner partnership. While it can be difficult to measure the direct impact of participating, we typically receive positive reinforcement from the student feedback. During an intern or full-time candidate interview students have commented about the classroom activity and remembered us from class.

\section{CONCLUSIONS}

It is from the AICPA Core Competency Framework that accounting educators are invited to provide students an exposure to the broad business perspective core competencies. These competencies coupled with the functional and personal competencies provide our students a platform on which to meet the accounting profession challenges of the $21^{\text {st }}$ century. The partnership of the professor and practitioner as they develop a classroom event model detailed in this paper highlights the broad business perspective competencies. By planning, structuring, implementing and assessing this event the educator adds value to the importance and credibility of the education offered in the classroom and reinforced by the practitioner; while at the same time opening up a realistic view of the business world (through broad business perspective core competencies) our students will face in a few months.

\section{REFERENCES}

1. Accounting Education Change Commission (1990). Objectives of education for accountants: Position statement number one. Issues in Accounting Education, 5(2), 307-312.

2. Albrecht, W. S. and Sack, R. J.,(2000). Accounting Education: Charting the course through a perilous future, Accounting Education Series, 16, American Accounting Association, Sarasota FL.

3. American Accounting Association Committee on the Future Structure, Content, and Scope of Accounting Education (1986). Future accounting education: Preparing for the expanding profession. Issues in Accounting Education 1, 168-195.

4. American Institute of Certified Public Accountants (AICPA). (1999). AICPA core competency framework for entry into the accounting profession. Available from http://www.aicpa.org/edu/corecomp.htm.

5. American Institute of Certified Public Accountants (AICPA). (1998). CPA Vision Project- 2011 and Beyond. Available from http://www.cpavision.org/ resources.htm.

6. Big Eight White Paper (1989). Perspectives on education: Capabilities for success in the accounting profession, New York: Arthur Andersen \& Co., Arthur Young, Coopers and Lybrand, Deloitte Haskins \& Sells, Ernest and Whinney, Peat Marwick Main \& Co., Price Waterhouse, and Touche Ross.

7. Fouch, S.R. (2004) Developing functional and personal competencies through an interactive tax research case study. Journal of Accounting Education, 22(4), 275-281.

8. Kramer, B., Johnson, C., Crain, G., and Miller, S. (2005). The Practitioner-Professor Link. Journal of Accountancy, 199(6), 77-80. 


\section{EXHIBIT 1 \\ Student Survey Response $(n=64)$ \\ What things did you find helpful about the presentation?}

1. A look into the real world of professional accounting as a career.

2. Pretty much everything except when they talked about their new program.

3. They had good first hand experiences/answers.

4. In the next year or so I would like to join the young professional[s] of Milwaukee, I probably wouldn't have known about them if it wasn't mentioned.

5. How it was based on questions the students have about the profession.

6. Talking about the filing database, learning a little more about the lifestyle, working schedule for tax accountants.

7. What they look for in an employee. What types of things employees do during the tax season and off? How to become an intern there.

8. The question and answer period because it provided information that students really wanted to know.

9. $\quad$ The question and answer session was very informative.

10. What I thought was helpful was when he said stuff about the internship. For example, what to expect and the resume stuff was awesome to know from someone who actually looks at that. I thought that reading our questions was a good idea.

11. I found it extremely helpful to learn what their work hours are. It is very important to me to know what my lifestyle will be like. It also made me feel better about Kolb \& Co. should I ever think of working there.

12. To see how things really work in that field and hear a little about what they do helps to see what field you want to go into.

13. Learning about how the profession really handles tax season. Learning about how their company operates. Learning how tax professionals utilize computer systems to make their analysis. Discovering that everything covered in our class does have a real world application.

14. I thought they did a good job showing the paperless filing system and it was helpful to actually see them open the files up.

15. Discussion about what they look for on resumes.

16. I enjoyed the discussion about the profession itself. Not so formal on specific tax law.

17. Learning how they see interns. They seem to respect them. That's a good thing.

18. The flexibility of work schedule after tax season.

19. Describing the computer system.

20. I liked the fact that the presentation really just involved answering our questions rather than a presentation followed by a Q \& A period.

21. I really like the fact that the girl was still in her early years and could relate to us and our current situation more than older speakers.

22. Learned a lot of interesting facts. Class was fun that day.

23. I liked how they answered as many questions as they could while they were here. I liked the tax quiz. It broke up the [presentation] and got us involved.

24. I learned more on what accountants do for a living both during and not during tax time. I got a sense of how they all work together to get the job accomplished.

25. I found their real life experience and how their busy season works very helpful. It was also appealing about their work schedule and the amount of time they get off in the non-busy season.

26. Bringing in a Whitewater grad because it makes it easier for us to relate to her. Talking about the fun things they do besides just taxes. Took the time to answer our questions.

27. They answered our questions and showed a real life perspective of what and how they do their taxes.

28. I thought the presenters did a good job answering the questions the class had prepared.

29. It really gave an inside perspective of daily duties, job expectations, and future career goals.

30. Information on how a CPA firm works, namely their tax department. Provided insight on a career.

31. I think the presentation gave valuable information about beginning a career in accounting and also what to expect in an accounting career.

32. I learned a great amount about Kolb \& Co. Learned abut other skills needed for the career. Learned some things about software used in the tax field.

33. I found it beneficial to hear what they did on a day to day basis.

34. I liked what they could share about the busy and non-busy season for tax accountants.

35. I liked the format of the presentation. This information will help me analyze where I want to go with my career. Being able to ask our own questions and get them answered can be very beneficial.

36. I got a good understanding of how things are changing in the accounting [profession] and what it would be like doing what they do.

37. It was helpful that they spent most of the time answering our questions and not just talking about Kolb the whole time. 
38. I thought the presentation was strongest when the speakers addressed their work environment (i.e., what was expected of them, hours, what they liked about working at their firm). Also the prizes/gifts were way cool.

39. The explanations and answers to our questions were most helpful. Our ability to ask additional questions were helpful too.

40. Real life examples were useful and helped me to understand some of the concepts better. The fun facts tax sheet was helpful and informative.

41. It was interesting to learn how they are going paperless because I have worked with case-ware at my job, so it made sense. It was interesting to hear different aspects about a smaller tax firm because I'm still trying to decide what branch of accounting I want to enter.

42. I really like being able to hear about their professional workdays and how their job allows them free time. I really enjoyed their visit.

43. The answers to questions regarding what it is like working at an accounting firm everyday.

44. It was informative and gave a sense of what it would be like in the real world.

45. I learned that there are opportunities with firms for finance majors as well.

46. The practical responses and insight provided to our questions and the overview of how they run their day-to-day operations. Everything was good. The format held my attention-switching back and forth between student questions and overview material.

47. The combined knowledge and obvious experience.

48. Hearing about job schedules and seeing the paperless forms they use and how many worksheets there are to help you get to the final form.

49. I liked the real-life examples and the demonstration of paper-less filing. I think having students write down questions and having you guys answer them was very beneficial.

50. The answered questions that the class had.

51. The presentation was interesting and informed me a lot about a public accounting firm. It was nice to see an illustration of the tax preparation software that the firm uses. The presentation also gave me an idea what to expect when I graduate and get out into my career.

52. It was fun doing the tax quiz and reminding ourselves about some of the things we had learned earlier in the year. Also it was good to hear about what goes on at their firm and their flexible work schedule because it gave me something to think about if I should want to work for them.

53. I liked how it was based around our questions. The quiz was another good aspect of the presentation.

54. I liked hearing about the typical hours they work and about some of the different ethical issues that arise.

55. Good to see perspective from real world.

56. When the two people talked about what computer program they used was helpful to me because it gave me an idea [of] what I will probably use in the future.

57. Provided real-life experience in answering questions. Gave a lot of good information.

58. Just simply answering our questions was helpful in itself.

59. Gave insight into what a tax professional does.

60. I liked the part where you told us about real world experiences and the paperless tax system.

61. The real world experience questions were helpful. Some of the other content was over my head though.

62. I liked how you answered the questions that we had. I also liked the trivia quiz. I thought it was interesting to hear and learn abut different facts regarding tax.

63. Technical information in tax practice.

64. Going over new tax laws might help, but it doesn't affect me right now. 


\section{EXHIBIT 2}

Student Comments ( $n=64)$

What things do you think should be changed for future presentations?

1. $\quad$ Nothing or no response.(23)

2. Students ask their own questions.(2)

3. Include a short preview of the company.

4. I didn't think the quiz was very useful.

5. I didn't get any right on the quiz, but that was something fun to do. I didn't know any of the answers which was most likely the point.

6. It would be nice to know starting salaries. I suppose that is sensitive information.

7. $\quad$ More time to get through more questions.(6)

8. More planning because they seemed rushed at the end.

9. We don't need to hear how they get along or the atmosphere-sounded like a sales pitch.

10. Describe their company more. Talk about career opportunities.(4)

11. They could cover more questions if they did not elaborate so much.(3)

12. Do more things to get more people involved.

13. Show more on paperless tax return filing.

14. Have the student questions listed in order of importance.

15. I would like them to talk more about their background

16. Have a ready presentation available instead of Q \& A.

17. The paperless system was not that interesting to me.

18. More time spent on real- life examples of the computerized system.

19. Go over all quiz questions and then personal [Q\&A] questions.

20. The quiz questions should have been spaced out more through the presentation.

21. It would be better if there were more stories.

22. We do technical [questions] everyday in class, so the change of pace to personal experiences is preferred.

23. Keep the technology praise to a minimum.

24. Lose the quiz so we have more time for questions from students.

25. Maybe to not rely entirely on student questions.

26. More information about filing tax returns for clients.

\section{EXHIBIT 3}

Student Response $(n=64)$ Should we invite them back to do a presentation for next year's tax class?

\begin{tabular}{|c|c|c|}
\hline Response & Number & Percentage \\
\hline Yes & 62 & $96.8 \%$ \\
\hline No & 0 & $0 \%$ \\
\hline Indifferent & 1 & $1.6 \% \%^{*}$ \\
\hline Yes and No & 1 & $1.6 \% *$ \\
\hline Total & 64 & $100 \%$ \\
\hline
\end{tabular}

* Non-accounting major student.

** Student wanted to invite them and other firms to provide more balance to the presentation. 
NOTES 